\title{
Soja integral processada em dietas para codornas japonesas em postura
}

\section{Sergio Luiz de Toledo Barreto ${ }^{1}$, Weyllison César Oliveira Moura ${ }^{2}$, Renata de Souza Reis ${ }^{3}$, Lúcia Reiko Hosoda ${ }^{3}$, Gustavo Vaz Corrêa Maia ${ }^{3}$, Graciane de Miranda Pena ${ }^{3}$}

\author{
${ }^{1}$ Universidade Federal de Viçosa - Departamento de Zootecnia, s/n, Campus Universitário - Viçosa, MG. \\ ${ }^{2}$ Mestrando em Zootecnia/Universidade Federal de Viçosa. \\ ${ }^{3}$ Graduando em Zootecnia/Universidade Federal de Viçosa.
}

RESUMO - Objetivou-se avaliar o desempenho de codornas japonesas na fase de postura alimentadas com dietas contendo soja integral processada. Utilizaram-se 320 codornas japonesas fêmeas com 29 semanas de idade e peso inicial de 186,1 \pm 4,0 g, distribuídas em delineamento inteiramente casualizado, com oito repetições, cada uma com dez aves por unidade experimental. As dietas foram isocalóricas e isonutritivas para proteína bruta, lisina digestível, metionina + cistina digestível, cálcio, fósforo disponível e sódio. Assim, foram avaliadas uma dieta controle, à base de milho e farelo de soja, e outras três, com substituição parcial do farelo de soja por soja integral tostada, extrusada ou micronizada, de modo que a soja integral forneceu 50\% da proteína bruta proporcionada pelo farelo de soja na dieta controle. Não foram observadas diferenças na produção e na massa de ovos, na conversão alimentar, na viabilidade das aves, na porcentagem de ovos comercializáveis, no peso específico dos ovos, na porcentagem de gema e de albúmen nem na porcentagem de casca dos ovos. A substituição de farelo de soja por soja integral tostada ocasionou redução no consumo de ração. Não foram observadas diferenças nos parâmetros estudados quando o farelo de soja foi substituído por soja integral extrusada. A substituição de farelo de soja por soja integral micronizada reduziu a variação de peso corporal das codornas, resultando em perda de peso das aves. O farelo de soja pode ser substituído, em 50\% da proteína, por soja integral tostada ou extrusada em dietas para codornas japonesas em postura. Entretanto, a substituição do farelo de soja por soja integral micronizada, em $50 \%$ da proteína, é desaconselhável, pois piora o desempenho, ocasionando principalmente perda de peso das aves.

Palavras-chave: Coturnix coturnix japonica, desempenho, qualidade de ovos, soja integral

\section{Processed whole soybean in diets for laying Japanese quails}

\begin{abstract}
This work aimed at evaluating the performance of Japanese quails fed diets with processed whole soybean during the laying phase. It was used 320 Japanese female quails at 29 weeks of age with an average weight of $186.1 \pm 4.0 \mathrm{~g}$ distributed in a complete randomized experimental design, with 8 replicates, each one with 10 quails per experimental unit. Diets were isocaloric and isonutritives for crude protein, digestible lysine, digestible methionine + cystine, calcium, available phosphorus and sodium. Thus, it was evaluated a control diet based on corn and soybean meal, and three other diets with partial substitution of the soybean meal for roasted whole soybean, extruded or micronized, so the whole soybean supplied $50 \%$ of the crude protein provided by soybean meal in control diet. No differences were observed on egg production, egg mass, feed conversion, viability of the birds, percentage of commercial eggs, egg specific weight, percentage of yolk and albumen neither on egg shell percentage. Substitution of soybean meal for roasted whole soybean reduced feed intake. It was not observed any differences in the studied parameters when soybean meal was replaced by extruded whole soybean. Substitution of soybean meal for micronized whole soybean reduced body weight variation of the quails, resulting in weight loss of the birds. Soybean meal can be substituted, in $50 \%$ of the protein, by roasted or extruded whole soybean in diets for laying Japanese quails. However, substitution of the soybean meal for micronized whole soybean, in $50 \%$ of the protein, is not recommended, because it worsens the performance results, mainly causing weight loss of the birds.
\end{abstract}

Key Words: Coturnix coturnix japonica, egg quality, performance, whole soybean

\section{Introdução}

A coturnicultura brasileira tem apresentado acelerado crescimento nos últimos anos. Entre os anos 2000 e 2005 o rebanho de codornas cresceu 18,4\% e a produção de ovos de codorna cresceu 34,95\% (IBGE, 2007).

Essas altas taxas de crescimento indicam a necessidade de investimentos e pesquisas para manter a coturnicultura 
como uma atividade economicamente viável. A alimentação das aves é um dos aspectos que pode interferir nessa viabilidade, por representar grande parte dos custos relacionados à atividade.

O farelo de soja, principal ingrediente proteico em dietas para monogástricos no Brasil, apresenta ampla variação de preço, o que causa grande impacto nos custos da coturnicultura. Nesse contexto torna-se interessante a avaliação da viabilidade de utilização de alimentos alternativos ao farelo de soja.

Entre os alimentos alternativos, destaca-se a soja integral por possuir alto teor proteico (35 a 39\%). Entretanto, os fatores antinutricionais presentes no grão de soja têm limitado sua utilização na alimentação de aves. Com isso, diversas pesquisas têm sido realizadas para avaliar o uso de soja integral termicamente processada, em que os fatores antinutricionais foram minimizados, em dietas de frangos de corte e galinhas poedeiras.

Benati (1973) verificou piora na produção de ovos e na conversão alimentar ao substituir o farelo de soja por soja integral tostada na ração de galinhas poedeiras. Entretanto, a redução nos índices zootécnicos proporcionada pela inclusão de soja integral em dietas de aves está associada, em geral, ao seu inadequado processamento. Por outro lado, a soja adequadamente processada pode promover desempenho das aves equiparado àquele observado com a utilização de farelo de soja. Martins (1995) não encontrou diferenças significativas nos parâmetros produtivos de frangos de corte ao substituir farelo de soja por soja integral tostada. Waldroup \& Hazen (1978), trabalhando com galinhas poedeiras, observaram maior produção de ovos ao substituir o farelo de soja pela soja integral extrusada em rações isonutritivas.

Entretanto, o assunto é ainda inexplorado para codornas, sendo que a extrapolação dos resultados obtidos com outras categorias de aves para essa espécie pode não resultar em índices zootécnicos satisfatórios.

Desse modo, este trabalho foi realizado com o objetivo de avaliar o desempenho de codornas japonesas na fase de postura alimentadas com dietas contendo soja integral tostada, extrusada ou micronizada.

\section{Material e Métodos}

O experimento foi realizado no setor de Avicultura do Departamento de Zootecnia do Centro de Ciências Agrárias da Universidade Federal de Viçosa, Minas Gerais, no período de janeiro a abril de 2006.

Foram utilizadas 320 codornas japonesas fêmeas (Coturnix coturnix japonica) com 29 semanas de idade e peso inicial de 186,1 \pm 4,0 g, provenientes da granja Fujikura (Suzano, São Paulo) com 1 dia de idade, criadas e recriadas no setor de Avicultura da Universidade Federal de Viçosa. O período experimental foi de 84 dias. As aves alojadas em gaiolas de arame galvanizado, com as dimensões de $47 \times 23,5 \times 16 \mathrm{~cm}$ (comprimento $\times$ largura $\times$ altura), dispostas em duas baterias com três andares cada. Foram alojadas dez aves em cada gaiola, fornecendo área de $110,4 \mathrm{~cm}^{2} /$ ave.

Os comedouros e os bebedouros utilizados foram do tipo calha, em chapa metálica galvanizada, ambos percorrendo toda a extensão das gaiolas: os comedouros na face frontal das baterias e os bebedouros na face posterior. As dietas e a água foram fornecidas à vontade durante todo o período experimental.

A temperatura ambiente do galpão foi verificada por meio de termômetro de máxima e mínima e a umidade relativa do ar por meio de termômetro de bulbo seco e bulbo úmido, ambos instalados junto às baterias. O programa de iluminação utilizado foi de 17 horas de luz diária, controlado por um relógio automático (timer).

O delineamento experimental foi inteiramente casualizado, com quatro dietas, oito repetições e dez aves por unidade experimental. Foram avaliadas uma dieta controle, à base de milho e farelo de soja, e outras três, com substituição parcial do farelo de soja por soja integral tostada, extrusada ou micronizada, de modo que a soja integral forneceu $50 \%$ da proteína bruta proporcionada pelo farelo de soja na dieta controle (Tabela 1).

As dietas foram isocalóricas e isonutritivas para proteína bruta, lisina digestível, metionona + cistina digestível, cálcio, fósforo disponível e sódio. As mesmas foram formuladas para atender as exigências nutricionais das codornas segundo as recomendações do NRC (1994), exceto para as exigências de metionina + cistina e lisina digestíveis, em que foram utilizadas aquelas verificadas por Pinto et al. (2003a, b), respectivamente, e para cálcio, verificada por Barreto et al. (2007). Os valores de composição dos alimentos utilizados foram aqueles apresentados por Rostagno et al. (2005).

Foram realizadas análises de atividade ureática e solubilidade protéica do farelo de soja e das sojas integrais, segundo métodos descritos em Sindirações (1998). Os resultados indicam que o farelo de soja e as sojas integrais foram submetidos a adequado processamento, conforme recomendações de ANFAR (1998), para atividade ureática, e de Butolo (2002), Nunes et al. (2001) e Araba \& Dale (1990), para solubilidade proteica (Tabela 2). 
Tabela 1 - Composição das dietas experimentais, com base na matéria natural

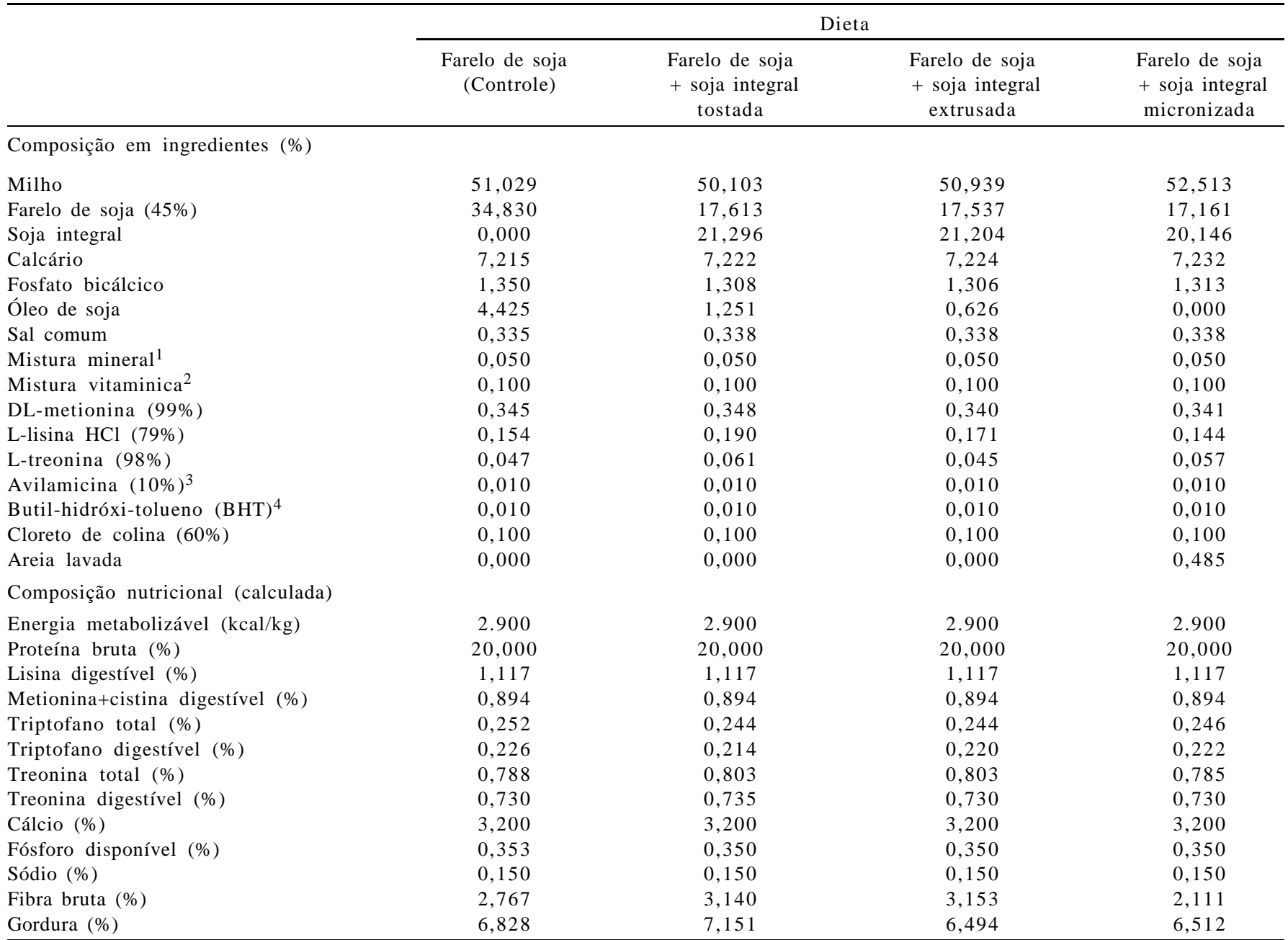

${ }_{1}^{1}$ Composição/kg de produto: $\mathrm{Mn}-160 \mathrm{~g} ; \mathrm{Fe}-100 \mathrm{~g} ; \mathrm{Zn}-100 \mathrm{~g} ; \mathrm{Cu}-20 \mathrm{~g}$; Co - 2 g; I - 2 g; excipiente q.s.p. - 1.000 g.

2 Composição/kg de produto: vit. A - 12.000 .000 U.I.; vit. $\mathrm{D}_{3}-3.600 .000$ U.I.; vit. E - 3.500 U.I.; vit $\mathrm{B}_{1}-2.500 \mathrm{mg}$; vit. $\mathrm{B}_{2}-8.000 \mathrm{mg}$; vit $\mathrm{B}_{6}-5.000 \mathrm{mg}$; ácido pantotênico - $12.000 \mathrm{mg}$; biotina - $200 \mathrm{mg}$, vit. K - $3.000 \mathrm{mg}$; ácido fólico - $1.500 \mathrm{mg}$; ácido nicotínico - $40.000 \mathrm{mg}$; vit. B 12 - $20.000 \mathrm{mg}$; Se - $150 \mathrm{mg}$; veículo q.s.p. - 1.000 g.

3 Promotor de crescimento.

${ }^{4}$ Antioxidante.

Os parâmetros avaliados foram: consumo de ração, consumo de lisina, produção de ovos, peso médio dos ovos, massa de ovos, conversão alimentar para dúzia de ovos, conversão alimentar para massa de ovos, variação de peso corporal, viabilidade das aves, percentagem de ovos comercializáveis, peso específico dos ovos e componentes dos ovos (porcentagem de gema, albúmen e casca).

A porcentagem de ovos comercializáveis foi obtida dividindo-se o número de ovos comercializáveis pelo número

Tabela 2 - Atividade ureática e solubilidade em hidróxido de potássio $(\mathrm{KOH})$ do farelo de soja e das soja

\begin{tabular}{lcc}
\hline Tipo de soja & $\begin{array}{c}\text { Atividade } \\
\text { ureática }(\Delta \mathrm{pH})\end{array}$ & $\begin{array}{c}\text { Solubilidade proteica } \\
\text { em KOH }(\%)\end{array}$ \\
\hline Farelo de soja & 0,09 & 85,4 \\
Soja integral tostada & 0,07 & 70,2 \\
Soja integral extrusada & 0,12 & 87,6 \\
Soja integral micronizada & 0,16 & 78,6 \\
\hline
\end{tabular}

total de ovos e multiplicando por 100. O número de ovos comercializáveis foi obtido descontando-se o total de ovos de casca fraca ou sem casca do total de ovos produzidos durante o experimento.

Para medição do peso específico dos ovos, a cada intervalo de 21 dias do período experimental, todos os ovos íntegros produzidos no $16^{\circ}, 17^{\circ}$ e $18^{\circ}$ dias do respectivo intervalo foram imersos em soluções aquosas de $\mathrm{NaCl}$ com densidades variando de 1,055 a $1,100 \mathrm{~g} / \mathrm{cm}^{3}$, com intervalos de $0,005 \mathrm{~g} / \mathrm{cm}^{3}$ entre si. Ao final do experimento foi calculada a média dos valores obtidos a cada intervalo. As densidades das soluções foram medidas por meio de um densímetro modelo INCOTERM-OM-5565.

Para avaliação dos componentes dos ovos, a cada intervalo de 21 dias do período experimental foram utilizados aleatoriamente quatro ovos de cada unidade experimental em cada dia de avaliação, durante os três últimos dias do 
respectivo intervalo. Os ovos foram pesados em balança com precisão de $0,001 \mathrm{~g}$. A seguir, as gemas foram separadas e pesadas, e as cascas lavadas e secas ao ar, para posterior obtenção do peso da casca. O peso do albúmen foi obtido subtraindo-se, do peso do ovo, o peso da gema e da casca.

As análises estatísticas dos parâmetros foram realizadas utilizando-se o programa SAEG - Sistema para Análises Estatísticas e Genéticas (UFV, 2004). Na ocorrência de efeito significativo, as médias foram comparadas pelo teste Tukey a 5\% de probabilidade.

\section{Resultados e Discussão}

As médias das temperaturas mínimas e máximas e umidade relativa do ar durante o período experimental foram $21,2 \pm 1,78^{\circ} \mathrm{C}, 29,9 \pm 4,44^{\circ} \mathrm{C}$ e $81,2 \pm 5,36 \%$, respectivamente. O consumo de ração entre as aves mantidas com a dieta com soja integral tostada foi $6,8 \%$ inferior ao obtido com a dieta controle (Tabela 3). Essa diferença pode ser explicada pela baixa granulometria da dieta com soja integral tostada, pois a soja foi finamente moída, o que resultou numa dieta com menor granulometria em relação à dieta controle (observação visual), o que pode ter dificultado a apreensão e deglutição do alimento pelas aves, reduzindo o consumo.

Não foram observadas diferenças no consumo de ração entre as aves que receberam as dietas contendo soja integral extrusada ou soja integral micronizada e aquelas que receberam a dieta controle. Resultados divergentes foram relatados por Waldroup \& Hazen (1978), que, em galinhas poedeiras, não observaram diferenças no consumo de ração quando substituíram farelo de soja por soja integral tostada, ao passo que o consumo de ração foi menor quando forneceram ração com soja integral extrusada em substituição ao farelo de soja. Por outro lado, Faria et al. (1995), em experimento com galinhas poedeiras, e Martins (1995) e Laurentiz et al. (1995) com frangos de corte, não encontraram diferenças significativas no consumo de ração quando substituíram o farelo de soja por soja integral tostada ou micronizada. Benati (1973) também substituiu o farelo de soja da ração por soja integral tostada e não encontrou diferença significativa no consumo de ração de galinhas poedeiras.

Nesta pesquisa, os valores de consumo de ração foram semelhantes entre as dietas com soja integral processada. Resultado diferente foi verificado por Waldroup \& Hazen (1978), que, em experimento com galinhas poedeiras, observaram que uma dieta contendo soja integral tostada proporcionou maior consumo de ração em comparação a uma dieta contendo soja integral extrusada.

No grupo das aves alimentadas com a ração contendo soja integral tostada, o consumo de lisina foi 6,9\% inferior ao observado no grupo que recebeu a dieta controle. O mesmo não ocorreu com os grupos alimentados com as rações contendo soja integral extrusada e com soja integral micronizada, cujos consumos de lisina não diferiram do obtido com a dieta controle.

Nas aves alimentadas com a ração controle e com soja integral extrusada, o consumo de lisina digestível foi satisfatório, superior à exigência nutricional, de $254 \mathrm{mg}$ (Pinto et al., 2003b). Entretanto, as aves que receberam as dietas com soja integral tostada e soja integral micronizada apresentaram consumo de lisina 4,33\% e 2,76\% inferior à exigência, respectivamente.

A produção de ovos não foi influenciada pelas dietas, provavelmente pelo fato de que a atividade ureática das sojas foi abaixo do máximo recomendado (ANFAR, 1998). Portanto, os métodos de processamento permitiram adequado aproveitamento dos nutrientes necessários à produção de ovos. Esses resultados se assemelham aos encontrados por Faria et al. (1995), que não notaram

Tabela 3 - Parâmetros produtivos de codornas alimentadas com dietas contendo soja integral processada

\begin{tabular}{|c|c|c|c|c|c|}
\hline & \multicolumn{4}{|c|}{ Dieta } & \multirow[t]{2}{*}{ CV $(\%)^{1}$} \\
\hline & $\begin{array}{c}\text { Farelo de soja } \\
\text { (Controle) }\end{array}$ & $\begin{array}{c}\text { Farelo de soja } \\
+ \text { soja integral } \\
\text { tostada }\end{array}$ & $\begin{array}{c}\text { Farelo de soja } \\
+ \text { soja integral } \\
\text { extrusada }\end{array}$ & $\begin{array}{l}\text { Farelo de soja } \\
+ \text { soja integral } \\
\text { micronizada }\end{array}$ & \\
\hline Consumo de ração (g/ave/dia) ${ }^{2}$ & $23,4 a$ & $21,8 b$ & $23,1 \mathrm{ab}$ & $22,1 \mathrm{ab}$ & 4,53 \\
\hline Cons. de lisina dig. (mg/ave/dia) ${ }^{2}$ & $261 \mathrm{a}$ & 243b & 259ab & $247 \mathrm{ab}$ & 4,53 \\
\hline Produção de ovos (\%) & 91,4 & 89,2 & 89,3 & 87,8 & 5,22 \\
\hline Peso médio de ovos $(\mathrm{g})^{2}$ & $12,28 \mathrm{ab}$ & $12,08 \mathrm{ab}$ & $12,39 a$ & $11,98 b$ & 2,37 \\
\hline Massa de ovos (g/ave-dia) & 11,12 & 10,78 & 11,06 & 10,52 & 5,56 \\
\hline Conversão alimentar (kg/dúzia) & 0,303 & 0,293 & 0,313 & 0,310 & 7,48 \\
\hline Conversão alimentar (g/g) & 2,10 & 2,03 & 2,11 & 2,17 & 7,21 \\
\hline Variação de peso corporal $(\mathrm{g})^{3}$ & 4,25 & 1,60 & 2,21 & $-1,69$ & - \\
\hline Viabilidade (\%) & 95,0 & 92,5 & 95,0 & 90,0 & 7,99 \\
\hline
\end{tabular}

\footnotetext{
1 Coeficiente de variação.
}

${ }^{2}$ Médias seguidas de mesma letra na mesma linha não diferem $(\mathrm{P}>0,05)$ pelo teste Tukey.

${ }^{3}$ Foi feita análise descritiva desse parâmetro, pois os dados não seguiram distribuição normal. 
diferenças na produção de ovos quando substituíram o farelo de soja por soja integral tostada e soja integral extrusada nos níveis de 50 e 100\% para galinhas poedeiras, embora a soja integral tostada tenha apresentado atividade ureática muito alta (1,24). Da mesma forma, Waldroup \& Hazen (1978) substituíram o farelo de soja por soja integral tostada em rações para galinhas poedeiras e não observaram diferenças significativas na produção de ovos, mas constataram maior produção quando substituíram o farelo de soja por soja integral extrusada. Por outro lado, Benati (1973) verificou diminuição na produção de ovos quando utilizaram soja integral tostada em substituição ao farelo de soja em rações para galinhas poedeiras.

O uso de soja integral processada nas dietas influenciou o peso médio dos ovos, uma vez que, no grupo alimentado com a ração contendo soja integral extrusada, os ovos foram $3,42 \%$ mais pesados que os obtidos com a dieta contendo soja integral micronizada. O peso médio dos ovos não diferiu entre as dietas com soja integral processada e a dieta controle. Esses resultados se assemelham aos de Benati (1973) e Faria et al. (1995), que não observaram diferenças significativas no peso médio dos ovos quando utilizaram soja integral tostada ou soja integral extrusada em substituição ao farelo de soja em dietas para galinhas poedeiras. Por outro lado, Waldroup \& Hazen (1978) verificaram maior peso de ovo quando utilizaram soja integral tostada em comparação ao farelo de soja ou à soja integral extrusada em rações para galinhas poedeiras.

Neste trabalho houve, no entanto, diferenças em valores absolutos no peso médio dos ovos, uma vez que as dietas com soja integral tostada e soja integral micronizada proporcionaram valores 1,69\% e 2,44\% inferiores ao obtido com a dieta controle. Essas diferenças podem ser atribuídas ao menor consumo de lisina digestível das aves alimentadas com as rações com soja integral tostada e soja integral micronizada, que estariam abaixo da exigência nutricional da espécie.

Apesar do efeito das dietas sobre o peso médio dos ovos, a produção de massa de ovos produzida não apresentou diferenças significativas. De forma similar, Faria et al. (1995) não observaram diferenças na massa de ovos de galinhas poedeiras ao substituírem farelo de soja por soja integral tostada ou soja integral extrusada.

As conversões alimentares, tanto para dúzia de ovos como para massa de ovos, não foram influenciadas pelas dietas. Esses resultados indicam que os fatores antinutricionais remanescentes na soja após seu processamento não interferiram no aproveitamento do alimento para a produção de ovos. Resultado diferente foi encontrado por Waldroup \& Hazen (1978), que verificaram melhor conversão alimentar (g/ração/ovo) em galinhas poedeiras quando substituíram o farelo de soja da dieta por soja integral extrusada, mas não encontraram diferença nesse parâmetro quando utilizaram soja integral tostada em substituição ao farelo de soja. Ao contrário, Benati (1973) verificou piora na conversão alimentar (kg ração/dúzia de ovos) de galinhas poedeiras quando utilizaram soja integral tostada em substituição ao farelo de soja e atribuíram esse resultado ao inadequado processamento da soja integral.

As variações de peso corporal nas aves que receberam as dietas com soja integral tostada e soja integral extrusada foram, respectivamente, 62,35 e $48,00 \%$ menores que as observadas no grupo controle. Apesar dessas diferenças consideráveis, as dietas possibilitaram a manutenção do peso corporal das aves, que, por sua vez, é essencial para a produção de ovos e manutenção do peso dos ovos.

Entretanto, as aves que receberam as dietas com soja integral micronizada perderam peso durante o período experimental. Esse fato pode ser associado às variações no valor nutricional da soja integral micronizada, como no valor energético, decorrentes de seu processamento. Albino et al. (2006) avaliaram os valores de energia metabolizável aparente de alguns alimentos à base de soja para frangos de corte e encontraram valores de 3.757 e $1.942 \mathrm{kcal} / \mathrm{kg}$ para duas amostras de farinha integral de soja micronizada, comprovando que a qualidade nutricional da soja integral micronizada pode variar consideravelmente de um lote para outro. Para a formulação da dieta com soja integral micronizada, foi utilizado o valor de $3.660 \mathrm{kcal} / \mathrm{kg}$ (Rostagno et al., 2005). Caso o lote de soja integral micronizada utilizado no experimento tenha apresentado valor energético consideravelmente menor que o estabelecido, as aves não receberam, então, nível energético insuficiente para suas demandas, inclusive manutenção corporal.

A perda de peso nas aves que receberam a dieta com soja integral micronizada, apesar de baixa, refere-se ao período experimental de 84 dias. Entretanto, se essa taxa de perda de peso perdurasse ao longo do tempo de vida útil da codorna japonesa (370 a 380 dias) (Albino \& Barreto, 2003), as aves poderiam sofrer perda significativa de peso, o que poderia prejudicar o desempenho produtivo das codornas.

A viabilidade das aves não foi influenciada pelas dietas. Martins (1995) utilizaram soja integral tostada e soja integral extrusada para frangos de corte e também não verificou diferenças significativas nesse parâmetro.

Não foram observadas diferenças na porcentagem de ovos comercializáveis, portanto, a utilização de soja integral não interferiu na ocorrência de ovos de casca fraca ou sem casca. As dietas não tiveram efeito sobre o peso específico dos ovos e, considerando que esse parâmetro se correlaciona 
Tabela 4 - Qualidade de ovos de codornas alimentadas com dietas contendo soja integral processada

\begin{tabular}{|c|c|c|c|c|c|}
\hline & \multicolumn{4}{|c|}{ Dieta } & \multirow[t]{2}{*}{$\mathrm{CV}^{1}(\%)$} \\
\hline & $\begin{array}{l}\text { Farelo de soja } \\
\text { (Controle) }\end{array}$ & $\begin{array}{c}\text { Farelo de soja } \\
+ \text { soja integral } \\
\text { tostada }\end{array}$ & $\begin{array}{l}\text { Farelo de soja } \\
+ \text { soja integral } \\
\text { extrusada }\end{array}$ & $\begin{array}{c}\text { Farelo de soja } \\
+ \text { soja integral } \\
\text { micronizada }\end{array}$ & \\
\hline Ovos comercializáveis (\%) & 98,0 & 97,1 & 98,0 & 96,9 & 1,46 \\
\hline Peso específico $\left(\mathrm{g} / \mathrm{cm}^{3}\right)$ & 1,073 & 1,072 & 1,072 & 1,071 & 0,12 \\
\hline Gema (\%) & 29,00 & 29,73 & 29,93 & 29,85 & 1,74 \\
\hline Albúmen (\%) & 61,94 & 62,41 & 62,09 & 62,35 & 1,03 \\
\hline Casca $(\%)$ & 8,06 & 7,86 & 7,98 & 7,80 & 2,84 \\
\hline
\end{tabular}

${ }^{1}$ Coeficiente de variação.

positivamente com a qualidade da casca de ovos de galinha (Furtado et al., 2001), pode-se inferir que a adição de soja integral na dieta das codornas não afetou a qualidade da casca dos ovos.

Não foram observadas diferenças em nenhum dos componentes de ovo. Alguns dos nutrientes da dieta que podem interferir na qualidade dos ovos são cálcio, fósforo e aminoácidos essenciais, no entanto, como foram mantidos equivalentes na formulação das dietas experimentais, os resultados indicam que as sojas integrais disponibilizaram os nutrientes necessários para manutenção da qualidade dos ovos equiparada à do farelo de soja.

\section{Conclusões}

O farelo de soja pode ser substituído, em $50 \%$ da proteína, por soja integral tostada ou soja integral extrusada em dietas para codornas japonesas em postura. A substituição do farelo de soja por soja integral micronizada em dietas para codornas japonesas em postura é desaconselhável, pois piora o desempenho das aves, provocando principalmente perda de peso.

\section{Referências}

ALBINO, L.F.T.; BARRETO, S.L.T. Codornas: Criação de codornas para produção de ovos e carne. Aprenda Fácil, Viçosa, MG, 2003. 289p

ALBINO, L.F.T.; NERY, L.R.; ROSTAGNO, H.S. et al. Valores energéticos e composição química de alguns alimentos à base de soja usados na alimentação de frangos de corte In: CONFERÊNCIA APINCO 2006 DE CIÊNCIA E TECNOLOGIA AVÍCOLAS, 2006, Santos. Anais... Campinas: FACTA, 2006. p.117.

ASSOCIAÇÃO NACIONAL DOS FABRICANTES DE RAÇÕES ANFAR. Matérias-primas para a alimentação animal. São Paulo, 1998. 197p.

ARABA, M.; DALE, N.M. Evaluation of protein solubility as an indicator of under processing soybean meal. Poultry Science, v.69, p.1749-1752, 1990.

BARRETO, S.L.T.; PEREIRA, C.A.; UMIGI, R.T. et al. Determinação da exigência nutricional de cálcio de codornas japonesas na fase inicial do ciclo de produção. Revista Brasileira de Zootecnia, v.36, n.1, p.68-78, 2007.
BENATI, M. Efeito da soja integral na alimentação de poedeiras. 1973. 50f. Dissertação (Mestrado em Zootecnia) Universidade Federal de Viçosa, Viçosa, MG

BUTOLO, J.E. Qualidade de ingredientes na alimentação animal. Campinas: Colégio Brasileiro de Nutrição Animal, 2002. 430p.

FARIA, D.E.; JUNQUEIRA, O.M.; SAKOMURA, N.K. et al. Utilização da soja integral tostada e extrusada em rações para poedeiras comerciais. Revista Brasileira de Zootecnia, v.24, n.5, p.747-758, 1995.

FURTADO, I.M.; OLIVEIRA, A.I.G.; FERREIRA, D.F. et al. Correlação entre medidas da qualidade da casca e perda de ovos no segundo ciclo de produção. Revista Ciência Agrotécnica, v.25, n.3, p.654-660, 2001

INSTITUTO BRASILEIRO DE GEOGRAFIA E ESTATÍSTICA IBGE. Sistema IBGE de Recuperação Automática - SIDRA. Disponível em: <http://www.sidra.ibge.gov.br> Acesso em: 8/2/2007.

LAURENTIZ, A.C.; SAKOMURA, N.K.; SILVA, R. et al. Avaliação das sojas integrais tostada e extrusada sobre o desempenho de frangos de corte. In: CONFERÊNCIA APINCO' 95 DE CIÊNCIA E TECNOLOGIA AVÍCOLAS, 1995, Curitiba. Anais... Curitiba: FACTA, 1995. p.121-122.

MARTINS, I.B. Efeito do tratamento térmico sobre a qualidade nutricional do grão de soja no desempenho e na composição de carcaça de frangos de corte. 1995. 170f. Dissertação (Mestrado em Zootecnia) - Faculdade de Agronomia da Universidade Federal do Rio Grande do Sul, Porto Alegre.

NATIONAL RESEARCH COUNCIL - NRC. Nutrient requirements of poultry. 9.ed. Washington: National Academy of Sciences, 1994. 155p.

NUNES, R.V.; BUTERI, C.B.; NUNES, C.G.V. et al. Fatores antinutricionais dos ingredientes destinados à alimentação animal. In: SIMPÓSIO SOBRE INGREDIENTES NA ALIMENTAÇÃO ANIMAL, Campinas. Anais... Campinas: CBNA, 2001. p.235-245.

PINTO, R.; DONZELE, J.L.; FERREIRA, A.S. et al. Exigência de metionina mais cistina para codornas japonesas em postura. Revista Brasileira de Zootecnia, v.32, n.5, p.1166-1173, 2003a.

PINTO, R.; FERREIRA, A.S.; DONZELE, J.L. et al. Exigência de lisina para codornas japonesas em postura. Revista Brasileira de Zootecnia, v.32, n.5, p.1182-1189, 2003b.

ROSTAGNO, H.S.; ALBINO, L.F.T.; DONZELE, J.L. et al. Tabelas brasileiras para aves e suínos: composição de alimentos e exigências nutricionais. 2.ed. Viçosa, MG: Universidade Federal de Viçosa, 2005. 186p.

UNIVERSIDADE FEDERAL DE VIÇOSA - UFV. SAEG - Sistema para Análises Estatísticas e Genéticas. Versão 9.0. Viçosa, MG, 2004.

SINDIRAÇÕES - Sindicato Nacional da Indústria de Alimentação Animal. Compêndio brasileiro de alimentação animal. São Paulo: SINDIRAÇÕES, 1998. p.31-60.

WALDROUP, P.W.; HAZEN, F.R. An evaluation of roasted extruded and raw unextracted soybeans in the diet of laying hens. Nutrition Reports International, v.18, p.99-103, 1978. 